\title{
A Bio-inspired Multifunctionalized Silk Fibroin
}

\author{
Sofia Santi, Ines Mancini, Sandra Dire, Emanuela Callone, Giorgio Speranza, Nicola Pugno, \\ Claudio Migliaresi, and Antonella Motta*
}

ABSTRACT: A bio-inspired multifunctionalized silk fibroin (BMS) was synthesized in order to mimic the interaction of nidogen with the type IV collagen and laminin of basement membranes. The designed BMS consists of a motif of laminin achain-derived, called IK peptide, and type IV collagen covalently bound to the silk fibroin (SF) by using EDC/NHS coupling and a $\mathrm{Cu}$-free click chemistry reaction, respectively. Silk fibroin was chosen as the main component of the BMS because it is versatile and biocompatible, induces an in vivo favorable bioresponse, and moreover can be functionalized with different methods. The chemical structure of BMS was analyzed by using X-ray photoelectron spectroscopy, attenuated total reflection-Fourier transform infrared, cross-polarization magic angle spinning nuclear magnetic resonance techniques, and colorimetric assay. The SF and BMS solutions were cross-linked by sonication to form hydrogels or casted to make films in order to evaluate and compare the early adhesion and viability of MRC5 cells. BMS hydrogels were also characterized by rheological and thermal analyses. KEYWORDS: silk fibroin, laminin peptide, chemical modification, tissue regeneration, biomimetic

\section{INTRODUCTION}

molecules. It has several actions: providing biochemical and

The use of silk fibroin for the fabrication of biomedical mechanical signaling to cells and facilitating intercellular and prostheses and tissue engineering scaffolds has been widely intracellular interactions, modulating cell behavior, ${ }^{6,7}$ and investigated in the past years. The molecular structure of the regulating tissue development, function, and repair.

silk fibroin (SF), i.e., the protein composing the core part of The BM marks the paths for cell migration and works as a the silkworm filament, consists of a light chain $(\mathrm{Mw} \approx 26 \mathrm{kDa})$ charge-selective filtration barrier due to its net negative charge, and a heavy chain $(\mathrm{Mw} \approx 350 \mathrm{kDa})$ linked together by a regulating the passage of negative molecules from the blood disulfide bond.

other. ${ }^{1}$ The amino acid sequence of fibroin and the presence along the chain of RGD-like sequences are considered the main reasons for the favorable interactions that fibroin materials possess with cells and biological environments. ${ }^{2-5}$ Moreover, fibroin can be chemically conjugated with active peptides in order to achieve specific biological performances for selected applications.

Tissue engineering fixes the objective to produce cell supportive matrices in order to induce the regeneration of damaged tissues and organs. In general, the closer the scaffold

Hydrophilic groups are mainly present in the stream to tissues ${ }^{8,9}$ It is also a structural support for tissue and light chain, whereas the heavy chain has a primary structure body cavity wall development and performs an important role formed by repetitive sequences of GAGAGS, GAGAGY, and during the neural tissue remodeling, promoting synaptogenesis GAGAGVGY, mainly hydrophobic, that interact with each and myelination of nerves. ${ }^{10,11}$ is in terms of composition, morphology, and properties to the extracellular matrix, the faster and more effective the regeneration process will be.

The basement membrane (BM) is a sheet-like thin extracellular matrix that is essential for animal development. The BM mainly consists of laminin and type IV collagen,

Col(IV), interrelated with nidogen, perlecan, and other
The mimesis of the composition, structure, and functionality of the BM is still a challenge.

Previous studies reported the conjugation of laminin in different hydrogels based on collagen type I, hyaluronic acid, alginate, or polyacrylamide gels, failing in inducing the cooperation with Col(IV). ${ }^{12-14}$ In other cases, ${ }^{15,16}$ blends of laminin and Col(IV) have been made. Worth nothing is the fact that changes in the hydrogel's composition could negatively affect the cell behavior. For example, the loss of 


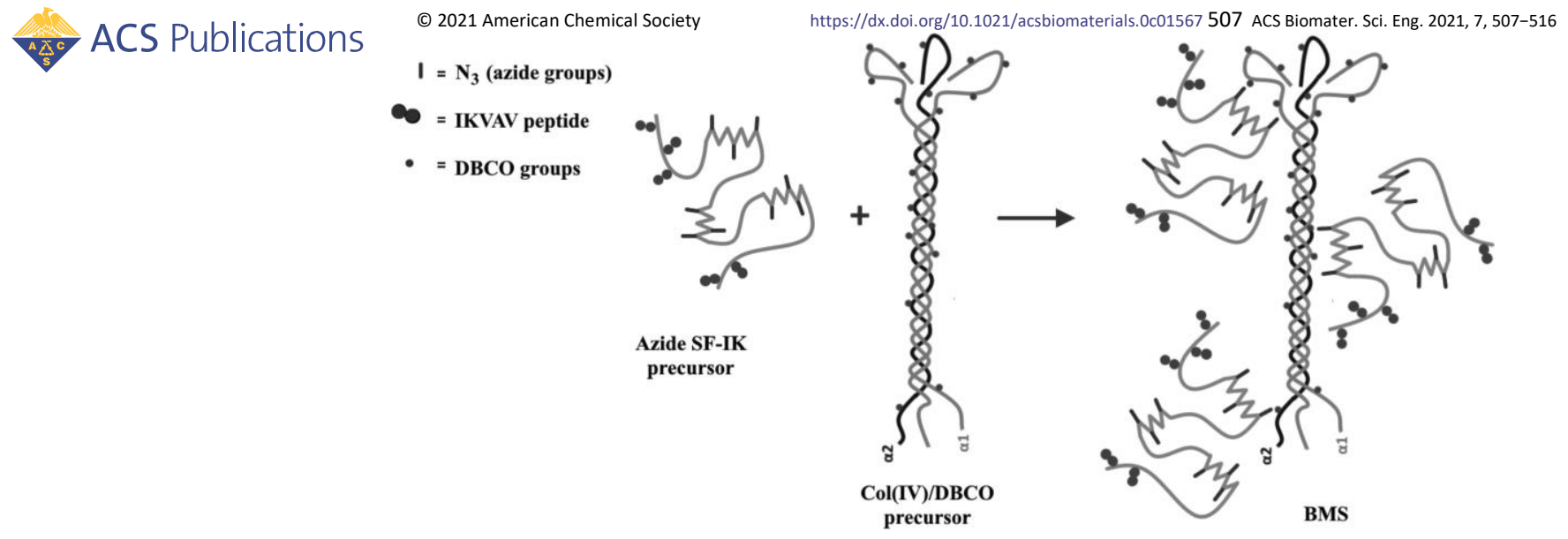

Figure 1. Structure design of Azide SF-IK, Col(IV)/DBCO, and the bio-inspired multifunctionalized silk fibroin (BMS). The BMS is formed after the click reaction between the precursors.

$\mathrm{Col}(\mathrm{IV})$ that is associated to the breakdown of the BM can start tumor invasion and metastases. ${ }^{17}$

In this work, silk fibroin was functionalized with IKVAV peptide (IK), belonging to the $\alpha$-chain of laminin that is involved in cell adhesion, migration, and differentiation, and covalently bound to Col(IV) in order to mimic the composition of the BM. ${ }^{7}$

The laminin peptide and the Col(IV) were attached on the same silk fibroin molecule to allow the interaction of the main components of the BM; otherwise, autoassembly phenomena could be preferentially promoted. ${ }^{9}$

The synthesis was conducted by using 1-ethyl-3-(3dimethylaminopropyl) carbodiimide in combination with Nhydroxysuccinimide (EDC/NHS method) and a strainpromoted azide-alkyne cycloaddition reaction (SPAAC), also termed as the $\mathrm{Cu}$-free click reaction, that occurs spontaneously in water. In particular, the EDC/NHS reaction was used to bind IK to the glutamic and aspartic acid residues, which represent the $3.3 \% \mathrm{~mol}$ of SF. ${ }^{18}$ The Col(IV) instead was bound to the silk fibroin chain by the $\mathrm{Cu}$-free click reaction, producing a triazole ring by cycloaddition. For this conjugation, the tyrosine groups (which represent the $5.2-5.5 \% \mathrm{~mol}$ of $\mathrm{SF})^{19}$ were functionalized with a diazonium coupling reaction that produced the Azide SF precursor. On the other hand, the Col(IV) was modified by adding an alkynederived unit, namely, dibenzocyclooctyne-sulfo$\mathrm{N}$-hydroxysuccinimidyl ester (DBCO-NHS), producing the Col(IV)/DBCO precursor.

The synthetic sequence to produce BMS can be summarized in three steps: (i) production of the Azide SF and Col(IV)/ DBCO precursors, (ii) coupling reaction of the Azide SF with IK by the EDC/NHS method to form the precursor "Azide SFIK", and finally, (iii) conjugation of Azide SF-IK with Col(IV)/ DBCO by using the SPAAC reaction to form the target BMS (Figure 1). All the reactions occur in aqueous solution.

The conversion of the reactions was verified by using qualitative and quantitative analyses. The BMS solution was gelled by sonication, and the hydrogel properties were characterized by thermal analysis and rheological measurements in comparison with a silk fibroin hydrogel. The SF and BMS solutions were also casted to make films that underwent biological analyses to determine the effect of the functionalization on the early adhesion and viability of human embryonic lung fibroblast cell line (MRC5).

\section{MATERIALS AND METHODS}

The following chemicals have been used: $\mathrm{N}$-(3-dimethylaminopropyl)-N'-ethylcarbodiimide hydrochloride (EDC), N-hydroxysulfosuccinimide sodium salt (NHS), 4-azidoaniline hydrochloride, ptoluenesulfonic acid monohydrate, collagen from human placenta (collagen IV), dibenzocyclooctyne-sulfo-N-hydroxysuccinimidyl ester (DBCO-NHS), sodium nitrite, acetonitrile, 2,4,6-trinitrobenzene sulfonic acid (TNBS) (Sigma Aldrich), laminin A chain (CliniSciences), MRC5 (human embryonic lung fibroblast cell line, ATCCCCL171), MEM (Minimum essential medium), fetal bovine serum (FBS), sodium pyruvate, L-glutamine (2 mM), antibiotic/antimycotic, nonessential amino acids, rhodamine-phalloidin, and 4',6-diamidino2-phenylindole (DAPI) (Thermo Fisher Scientific).

The multifunctionalization of silk fibroin was performed through the following consecutive steps:

(i) preparation of an SF solution in water;

(ii) functionalization of the SF with azide groups by a diazoniumcoupling reaction (Azide SF);

(iii) coupling of the Azide SF with the IK peptide (Azide SF-IK);(iv) production of the Col(IV)/DBCO precursor; and (v) synthesis of the bio-inspired multifunctionalized silk fibroin (BMS).

The single steps are described in the following.

(i) Silk fibroin solution preparation. Bombyx mori cocoons (purchased from Chul Thai SilkCo., Phetchabun, Thailand) ${ }^{20}$ were degummed by treating twice with $\mathrm{Na}_{2} \mathrm{CO}_{3}$ aqueous solution $(1.1 \mathrm{~g} / \mathrm{L})$ at $98{ }^{\circ} \mathrm{C}(1.5 \mathrm{~h}$ for each treatment $)$ and rinsed with distilled water. The 
degummed silk fibroin was dissolved in $9.3 \mathrm{M} \mathrm{LiBr}$ solution $(1 \mathrm{~g} / 10 \mathrm{~mL})$ at $65^{\circ} \mathrm{C}$ for $4 \mathrm{~h}$. The solution was dialyzed in a Slide-ALyzer Cassette (ThermoScientific), MWCO 3500 Da, against distilled water for 3 days.

(ii) Diazonium coupling reaction. The functionalization of silkfibroin with azide groups (Azide SF) was performed as follows. Solutions of 4-azidoaniline hydrochloride $(0.35 \mu \mathrm{mol})$ in $0.5 \mathrm{~mL}$ of a $1: 1$ acetonitrile/water solution, of p-toluenesulfonic acid monohydrate (1.2 $\mu \mathrm{mol})$ in $0.25 \mathrm{~mL}$ of water, and of sodium nitrite $(0.7 \mu \mathrm{mol})$ in $0.25 \mathrm{~mL}$ of water were initially prepared in an ice bath. At this stage, nitrosation of primary aromatic amines occurs with nitrous acid, which is generated in situ from sodium nitrite and the strong acid. The diazonium salt solution was added to $2 \mathrm{~mL}$ of $3 \%$ SF borate solution buffered $\mathrm{pH} 9.2(100 \mathrm{mM}$ sodium tetraborate and $150 \mathrm{mM}$ $\mathrm{NaCl}$ dissolved in deionized water). ${ }^{19}$ The reaction was carried out under stirring for $30 \mathrm{~min}$ at room temperature, and the resulting yellowish solution was finally dialyzed against phosphate buffered saline at $\mathrm{pH} 6$ for 1 day by using a SPECTRA/POR dialysis tubing (cutoff, $12 / 14 \mathrm{kDa}$ ). The final concentration of Azide SF resulted to be $3 \% \mathrm{w} / \mathrm{v}$, as estimated using a Thermo Scientific Nanodrop 1000 spectrophotometer (ND-1000).

(iii) Azide SF with IK peptide functionalization (Azide SF-IK). Theabove indicated solution $(2 \mathrm{~mL})$ was mixed with $12 \mathrm{mg}$ of EDC and $7.2 \mathrm{mg}$ of NHS for $20 \mathrm{~min}$ at room temperature

(RT) under gentle stirring. After $20 \mathrm{~min}$, the activated protein was purified by gel filtration using a desalting resin (Zeba Desalting Chromatography Cartridges). ${ }^{21}$ After purification, the activated protein solution was added drop by drop to a phosphate solution buffered at pH 7.4 containing $50 \mu \mathrm{L}$ of IK peptide $(2 \mathrm{mg} / \mathrm{mL})$ and left to react for $2 \mathrm{~h}$ under stirring at RT. The excess reactants were removed by desalting with a MWCO $7 \mathrm{kDa}$ column.

(iv) $\mathrm{Col}(\mathrm{IV}) / \mathrm{DBCO}$ precursor production. The Col(IV)/DBCOprecursor was prepared by reacting $2 \mu \mathrm{L}$ of DBCO-NHS ester/ PBS solution $(50 \mathrm{mg} / \mathrm{mL}, \mathrm{pH} 7.4)$ with $0.2 \mathrm{~mL}$ of $\mathrm{Col}(\mathrm{IV})(2.0 \mathrm{mg} / \mathrm{mL}, \mathrm{pH} 7.4)$ for $2 \mathrm{~h}$ at $4{ }^{\circ} \mathrm{C}$. The resulting solution was purified overnight by dialysis at $4{ }^{\circ} \mathrm{C}$ versus deionized water (ddw) by using a Slide-A-Lyzer Cassette (ThermoScientific) dialysis cassette (MWCO, 3.5 $\mathrm{kDa})$.

(v) Synthesis of the biomimetic multifunctionalized silk fibroin (BMS). The BMS was obtained combining $1 \mathrm{~mL}$ of $3 \%$ Azide SF-IK solution with $50 \mu \mathrm{g}$ of Col(IV)/DBCO precursor. Thus, the weight ratio between Azide SF-IK and Col(IV)/DBCO precursors was 600:1. The reaction occurred in $30 \mathrm{~min}$ at RT through a SPAAC reaction to obtain a final solution of $2 \%$ of BMS in water. For further steps, the solution has been concentrated by dialysis against polyethylene glycol to $3 \% \mathrm{w} / \mathrm{v}$. The efficiency of the Col(IV) reaction has been evaluated by spectroscopic analysis.

Hydrogel Preparation. BMS and SF water solutions, both at $3 \% \mathrm{w} / \mathrm{v}$ concentrations, were sonicated by using a Hielscher Ultrasound UP400S for $1^{\prime} 30^{\prime \prime}$ at $50 \%$ of amplitude. Gelation occurred approximately after $1 \mathrm{~h}$ at $37^{\circ} \mathrm{C}$.

Film Preparation. BMS and SF water solutions, both at $3 \% \mathrm{w} / \mathrm{v}$ concentrations, were casted in a 24 -well dish. After drying, the films were stabilized by methanol (80\%) for $10 \mathrm{~min}$ and washed with water three times.

Determination of Free-Amino Groups. Free-amino groups have been evaluated by using a 2,4,6-trinitrobenzene sulfonic acid (TNBS) method. Dynamic light scattering (DLS) measurements were also performed to verify the formation of aggregates, mainly in SF solutions, that prevent from exposing the free-amino groups. The content of free-amino groups (FAC) in Col(IV) and Col(IV)/DBCO was determined by using the TNBS method ${ }^{22,23}$ as follows: $150 \mu \mathrm{L}$ of $0.02 \%(\mathrm{w} / \mathrm{v})$ TNBS solution, prepared in a buffer of $0.1 \mathrm{M}$ sodium bicarbonate $\left(\mathrm{NaHCO}_{3}\right.$, $\mathrm{pH} 8.5)$, was mixed with $300 \mu \mathrm{L}$ of each sample $(0.2 \mathrm{mg} / \mathrm{mL})$ also buffered at $\mathrm{pH} 8.5$ by dialysis and heated at $40{ }^{\circ} \mathrm{C}$ for $2 \mathrm{~h}$. The protein concentration was confirmed by thermogravimetric analysis (TGA). After $2 \mathrm{~h}, 150 \mu \mathrm{L}$ of $10 \%$ of SDS and $75 \mu \mathrm{L}$ of $1 \mathrm{~N} \mathrm{HCl}$ was added to block the reaction. Instead, the SF and its derivative FAC contents were determined with slight changes from the above procedure to avoid gelation of fibroin. Each sample $(100 \mu \mathrm{L})$ was poured in a 96 -well plate, and absorbance was measured at $418 \mathrm{~nm}$ by using a microplate reader (Tecan Infinite M200). The FAC of each sample was estimated from a calibration curve of $\beta$-alanine (MW: $89.09 \mathrm{Da}$ ) solution in 0.1 $\mathrm{M}$ sodium bicarbonate in the range $0.5 \times 10^{-3}$ to $1.7 \times 10^{-5} \mathrm{M}$.

Evolution in Time of SF Aggregates in Solution. DLS analysis was used in order to evaluate possible aggregation phenomena in the SF solution, which could affect the absorption data acquired during TNBS detection, ${ }^{24}$ by using a Zetasizer, Malvern Nano series. The setting parameters were fixed as follows: 15 runs of $10 \mathrm{~s}$ each sample, equilibration time of $120 \mathrm{~s}$ at RT, silk fibroin RI $=1543, \mathrm{Ab}=0.01$, and dispersed in water.

Chemical Composition Characterization by X-ray Photoelectron Spectroscopy (XPS). A drop of SF and another one of BMS solutions were left to dry separately on a glass support and analyzed by using an Axis DLD Ultra analyzer from Kratos (UKManchester). The core lines of interest were acquired at a higher energy resolution using a pass energy of $20 \mathrm{eV}$ with charge compensation, being the samples nonconductive. Data reduction was performed using a made in-house software ${ }^{25}$ based on the R platform software.

Secondary Structure Characterization by ATR-FTIR (Attenuated Total Reflection-Fourier Transform Infrared) Spectroscopy. All SF-based compound solutions and their respective hydrogels were freeze-dried, and the secondary structures were analyzed by infrared spectroscopy using an instrument working in attenuated total internal reflection mode equipped with a zinc selenide crystal (ATR-FTIR, Bruker Tensor 27). Each spectrum was the mean of 128 acquisitions (in the regions 4000 and $400 \mathrm{~cm}^{-1}$ ) with a $4 \mathrm{~cm}^{-1}$ spectral resolution. Spectral analysis was performed using OriginPro 2017.

Solid-State Nuclear Magnetic Resonance (NMR) Spectroscopy. Nuclear magnetic resonance spectroscopy was conducted on SF, Azide SF, Azide SF-IK, and BMS lyophilized solutions. The test analyses were performed on ${ }^{13} \mathrm{C}$ nuclei by using a Bruker $400 \mathrm{WB}$ spectrometer (Bruker Corporation, Billerica, MA, USA) with a proton frequency of $400.13 \mathrm{MHz}$. The spectra were acquired with crosspolarization sequence under the following conditions: a ${ }^{13} \mathrm{C}$ frequency of $100.48 \mathrm{MHz}$, contact time of $2000 \mu \mathrm{s}$, decoupling length of $6.3 \mu \mathrm{s}$, recycle delay of $5 \mathrm{~s}$, and $41 \mathrm{k}$ scans. Samples were packed in $4 \mathrm{~mm}$ zirconia rotors, which were spun at $7 \mathrm{kHz}$ under air flow. Adamantane $\mathrm{CH}_{2}$ resonance at $38.5 \mathrm{ppm}$ was used as an external secondary reference. ${ }^{26}$ All the spectra were normalized on the C $\beta$ resonance of SF Ala ( $\delta$ around 17.3 ppm) because the Ala amino acids of IK peptide and Col(IV) contribute negligibly to the signal. 
Differential Scanning Calorimetry (DSC). Differential scanning calorimetry (DSC) was performed on about $1 \mathrm{mg}$ of SF, Azide SF, Azide SF-IK, BMS (SF IK/Col(IV)) lyophilized hydrogels, and Col(IV) and $0.2 \mathrm{mg}$ of 4-azidoaniline hydrochloride (source of azide groups introduced in the SF). Samples were analyzed in a punched crucible in a temperature-modulated DSC Q20 calorimeter (TA Instrument) from 20 to $320{ }^{\circ} \mathrm{C}$ at $3{ }^{\circ} \mathrm{C} / \mathrm{min}$, under fluxing nitrogen, with a modulation period of $40 \mathrm{~s}$ and a modulation amplitude of $\pm 0.5^{\circ} \mathrm{C}$. Glass transition $\left(\mathrm{T}_{\mathrm{g}}\right)$ and degradation $\left(\mathrm{T}_{\mathrm{d}}\right)$ temperatures and specific endothermic heat $(\Delta \mathrm{H})$ of each sample were determined.

Thermogravimetric Analysis (TGA). TGA analysis was conducted in a Mettler TG50 thermobalance on about 100 mg of water-equilibrated BMS hydrogels in comparison to SF, with nitrogen flowing at $100 \mathrm{~mL} \cdot \mathrm{min}^{-1}$, at a heating rate of $10 \mathrm{~K} \cdot \mathrm{min}^{-1}$, in the range $30-250{ }^{\circ} \mathrm{C}$.

Rheology. The rheological characterization of SF and BMS hydrogels was done with a Discovery HR-2 hybrid rheometer, in dynamic mode, on disk samples in triplicate (diameter of $3 \mathrm{~cm}$, height of $3.1 \mathrm{~mm}$ ). The strain sweep was set in the range of 1-100 Hz, with a strain of $5 \%$.

Biological Evaluation. MRC5 cells were cultured in the following medium composition: MEM (Minimum essential medium, $87 \%$ ), fetal bovine serum (10\%), sodium pyruvate ( $1 \%)$, L-glutamine $(2 \mathrm{mM}, 1 \%)$, antibiotic/antimycotic $(1 \%)$, and non-essential amino acids $(1 \%)$. The cells were cultured in T-75 cell culture flasks (Corning, New York) under standard culture conditions of $37{ }^{\circ} \mathrm{C}$ and $5 \%$ carbon dioxide. Cell adhesion and spreading were studied on hydrogels and films of modified and unmodified silk fibroin. The films were sterilized by using $70 \%$ ethanol for $30 \mathrm{~min}$ and washed three times with sterilized water, whereas hydrogels were produced by sterilizing the solutions by using a 0.22 $\mu \mathrm{m}$ filter and sonicating to induce gelation into a 24 -well dish. The samples were produced in triplicate for the adhesion test and in quadruplicate for evaluating cell viability.

Adhesion Test. The samples were incubated at $37{ }^{\circ} \mathrm{C}$ and $5 \% \mathrm{CO}_{2}$ for three time points $(1,3$, and 7 days). After each time point, the samples were washed with PBS and the cells were fixed with $4 \%$ paraformaldehyde in PBS for 30 min. The samples were washed again with PBS and permeabilized with $0.1 \%$ Triton-X100 in PBS for 30 min. After further washing in PBS, the cells were then treated for 30 min in a dark environment first with rhodamine-phalloidin to detect

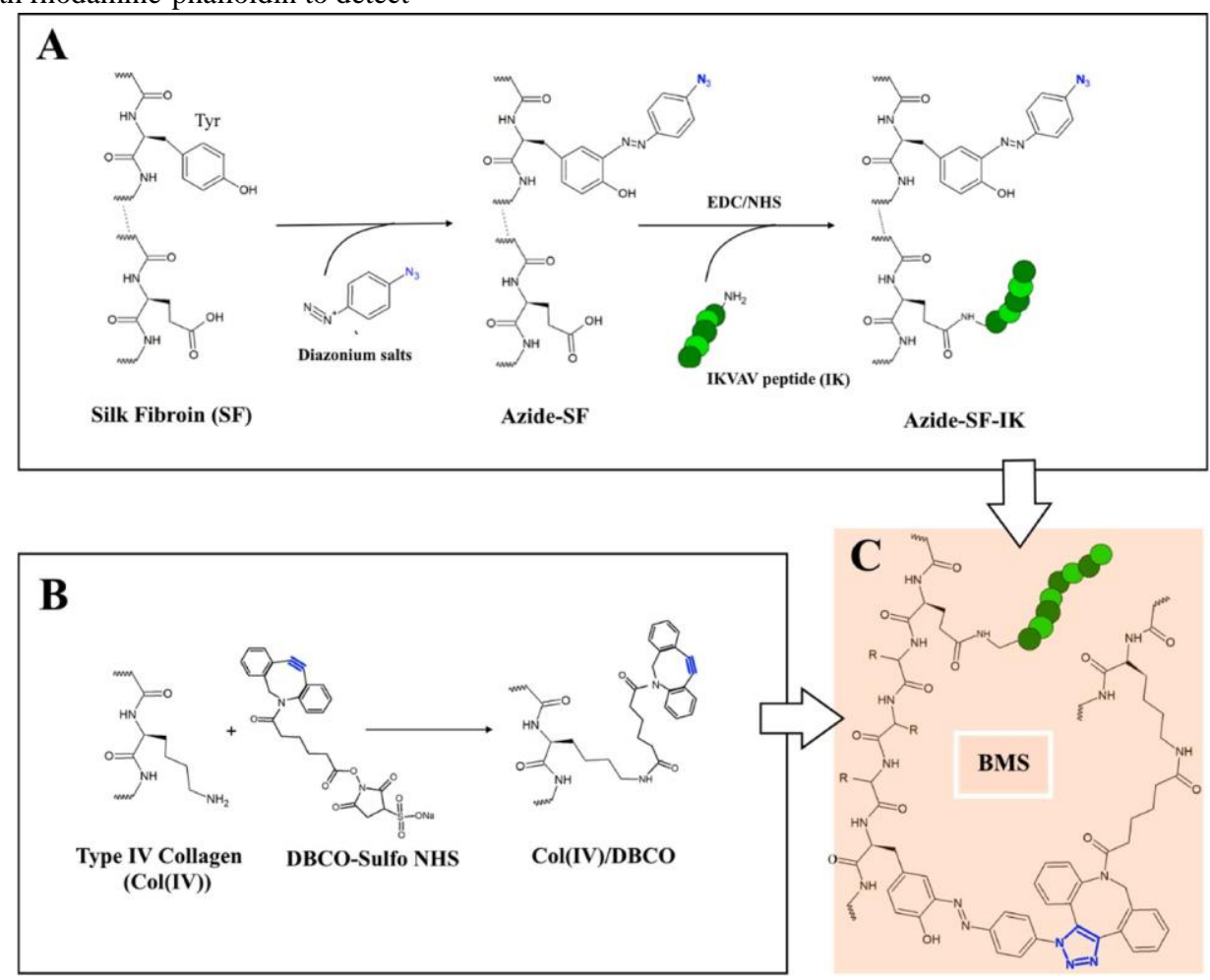

Figure 2. Synthetic sequence to obtain the biomimetic multifunctionalized silk fibroin (BMS): (a) conjugation of the azide-terminated SF with IK; (b) formation of the "Col(IV)/DBCO" precursor; and (c) reaction between Azide SF-IK and Col(IV)/DBCO to form the multifunctionalized silk fibroin (BMS). 
the cytoskeleton and with DAPI to counterstain the nuclei of the cells. They were imaged using a Nikon TE2000-S fluorescent microscope (Melville, New York). Unmodified SF hydrogels were used as controls.

Cell Viability. At each time point (days 1, 3, and 7), the culture medium was replaced with medium containing Alamar Blue $(10 \% \mathrm{v} /$ v) and data were recorded after around $3 \mathrm{~h}$ of incubation at $37^{\circ} \mathrm{C}$ by using a microplate reader, setting the absorbance at $535 \mathrm{~nm}$ and the emission at $590 \mathrm{~nm}$.

Cell Counting. The number of cells was determined by $4,6-$ diamidino-2-phenylindole (DAPI) fluorescence staining and counted by ImageJ software on different visual fields of $(1.5 \times 1.5 \mathrm{~mm})$ selected randomly.

\section{RESULTS AND DISCUSSION}

Synthesis of the Biomimetic Multifunctionalized Silk Fibroin Macromolecules (BMS). Figure 2 illustrates the synthesis of BMS.

The reactions were monitored by the TNBS assay. The FAC of SF conjugated with IK peptide was compared with that of SF that follows the same steps of the reaction without adding the peptide (the SF is subject to aging during dialysis as confirmed by DLS analysis, Supporting Information). The results show an increase of $0.3 \times 10^{-4} \mathrm{M}$ of free amines in SFIK compared to the SF (Supporting Information).

Instead, the Col(IV)/DBCO precursor shows a decrease in free amines of about 52\% compared to Col(IV), a value which reveals the efficiency of the reaction (Supporting Information). 13

C CPMAS NMR (cross-polarization magic angle spinning nuclear magnetic resonance) was performed to detect chemical shifts, line shapes, and any possible structural conformation changes during functionalization. The spectra shown in Figure 3 reveal a slight increase in the intensity of the carbonyl peak and the methylene resonances of Ala, Ser, and Tyr with the Figure 3. ${ }^{13} \mathrm{C}$ CPMAS NMR spectra of silk fibroin and modified fibroin. (A: alanine, G: glycine, S: serine, and Y: tyrosine).

peptide addition. In particular, the increase in the carbonyl peak ( $\delta$ around $172.7 \mathrm{ppm}$ ) might refer to the Ser/Gln/Asp of the IK peptide added. Instead, the peak of SF carbonyl groups ( $\delta$ around $56.1 \mathrm{ppm})^{27}$ results higher than that of BMS because of the presence of Ser/Tyr in the SF molecule, whereas the peak of carbonyl/carboxylic groups $(\delta \text { around } 172.7 \mathrm{ppm})^{28}$ of BMS is higher than that of SF because of the presence of Asn/Gln/Asp/Glu amino acids in BMS after the conjugation of the Col(IV). 
The percentage of Silk II was also evaluated following the description presented by Callone et al. $;{ }^{29}$ it decreases in Azide SF (36.6\%) compared to the SF (38.1\%), increases in the Azide SF-IK (43.6\%), and decreases again after the addition of the
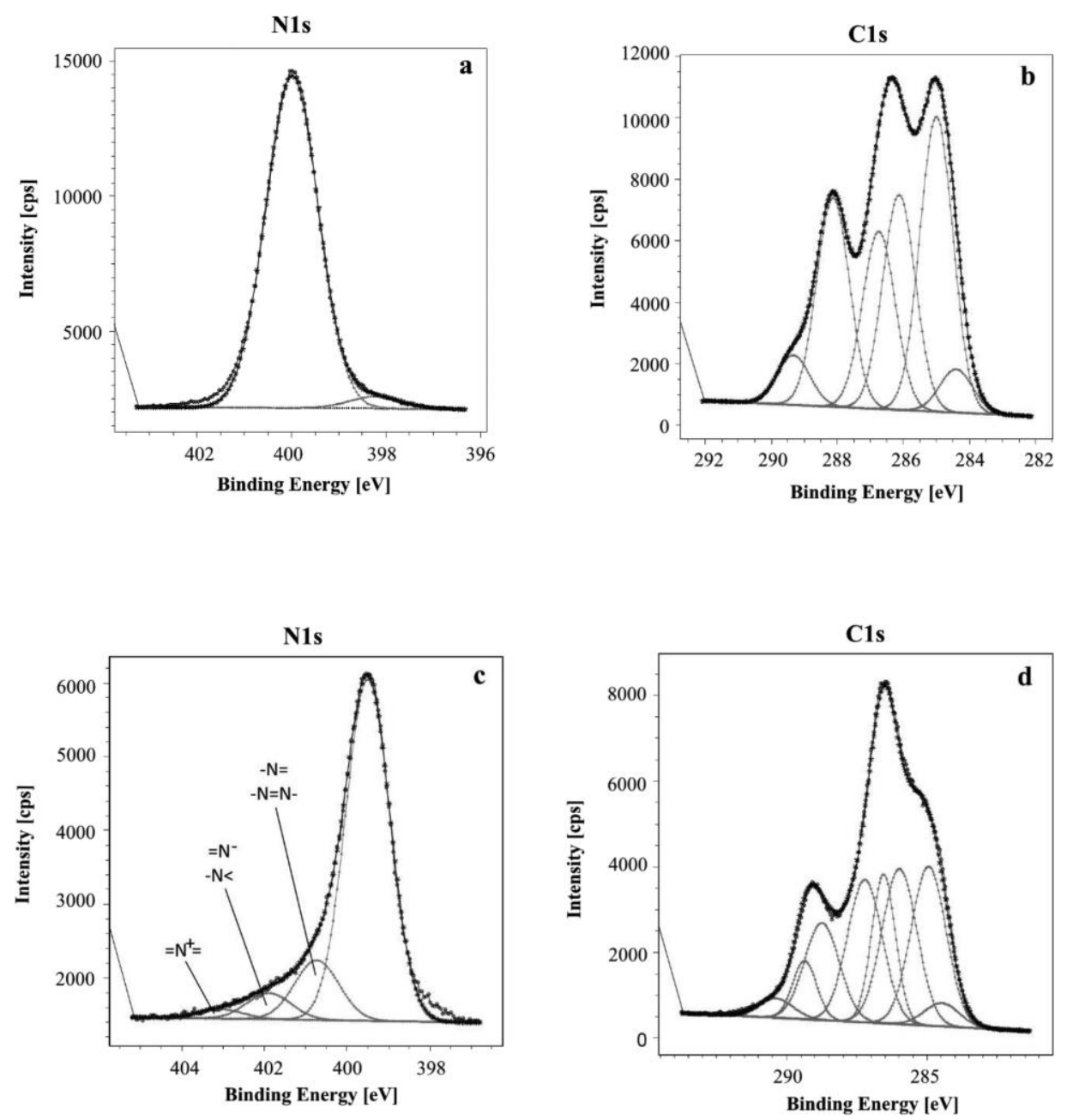

Figure 4. XPS core lines for (a and b) silk fibroin and (c and d) BMS.

Col(IV) (40.9\%), which might be due to the steric hindrances. XPS analysis was performed on SF and BMS in order to highlight the efficiency of the click reaction.

The N 1s core line of the SF shows two peaks at 400 and $398.3 \mathrm{eV}$ assigned, respectively, to Oal $-\mathrm{N}-$ and $\mathrm{N}$ in the amino acids displaying aromatic rings ${ }^{30,31}$ (Figure $4 \mathrm{a}$ ).

The six different peaks of the $\mathrm{C} 1 \mathrm{~s}$ core line of the $\mathrm{SF}$ (Figure $4 \mathrm{~b}$ ) can be ascribed to $-\mathrm{C}$ (a $(284.4 \mathrm{eV})$, to $\mathrm{CH}_{\mathrm{x}}(285 \mathrm{eV})$, to the $\mathrm{C}-\mathrm{N}$ bond $(285.9 \mathrm{eV})$, to $-\mathrm{C}$ - $\mathrm{O}(287.5 \mathrm{eV})$, to $\mathrm{O}$ C $\mathrm{C}-\mathrm{N}-(288 \mathrm{eV})$, and to $-\mathrm{O}-\mathrm{C}$ (2) $(289.5$

32-35

$\mathrm{eV})$. Spectral analysis revealed in SF an amount of carboxylic groups equal to $3.2 \% \mathrm{~mol}$ in accordance with the previously cited literature. ${ }^{18}$

The three components from the N 1s core line of BMS are evidenced in Figure $4 \mathrm{c}$ and transcribed in Table 1a. The acquired values are compared with the values of Table $1 \mathrm{~b}, \mathrm{c}$ where the components of unreacted azide $\left(-\mathrm{N}_{3}\right)$ and triazole, i.e., the bridge between Col(IV)/DBCO and Azide SF-IK, are, respectively, reported. ${ }^{34,36}$ The presence of the component at $403 \mathrm{eV}$ indicates that in the final BMS compound, $37 \%$ of azide, i.e., the ratio between the $403 \mathrm{eV}$ component in the free (Table 1b) and reacted azide (Table 1a), did not react. The $\mathrm{C}$ 1s core line (Figure 4d) of the BMS sample shows instead an increase in -C?O and C-N components for the presence of the Col(IV) hydrophilic amino acids.

The secondary structures of lyophilized SF, Azide SF, Azide SF-IK, and BMS solutions were characterized by ATR-FTIR. This analysis highlights mainly the functionalization of the SF tyrosines by diazonium coupling that change the stability and the conformation of the SF, as confirmed by the percentage of Silk II evaluated by CPMAS NMR. The vibrational absorption spectra are shown in Figure 5a. The significant bands $5,19,37-39$ at $1650 \mathrm{~cm}^{-1}$ (amide I), at $1540 \mathrm{~cm}^{-1}$ (amide II), and at $1236 \mathrm{~cm}^{-1}$ 
(amide III) are visible in all spectra. However, the shoulder at $1518 \mathrm{~cm}^{-1}$, corresponding to the $\beta$-sheet conformation, decreases in Azide SF, Azide SF-IK, and BMS with respect to SF, thus suggesting that a reduction of $\beta$-sheet content might be due to the $\mathrm{SF}$ and azide interaction. This seems to be confirmed by the absorbance band at $1412 \mathrm{~cm}^{-1}$ that represents the $\mathrm{C}-\mathrm{OH}$ bending vibration. ${ }^{26,40}$ In fact, the increasing of the $\mathrm{C}-\mathrm{OH}$ bending vibration after fibroin treatment with azide groups demonstrates a reduction of tyrosine functional groups involved in intra- and intermolecular hydrogen bonds between the hydrophobic side chains. In the curves related to lyophilized SF, Azide SF, Azide SFIK, and BMS hydrogels, no differences can be observed. Instead, as expected, the comparison with the curves of the corresponding solutions clearly shows a shift of the main peaks to lower wavelengths (Figure $5 \mathrm{~b}$ ) due to the transition to a $\beta$ sheet structure after sonication. In particular, the shifts from 1650 to $1622 \mathrm{~cm}^{-1}$, from 1540 to $1517 \mathrm{~cm}^{-1}$, and from 1236 Table 1. (a) Components of the SF-Col(IV). The -N? ? ? $\mathrm{N}^{-}$, and ? ? $\mathrm{N}^{+}$? Bonds Are Referred to as Azide Groups. The $-\mathrm{N}$ ? N- and $-\mathrm{N}<$ Bonds Are Referred to as Triazole Compounds. (b) Components of Azide Groups. (c) Components of Triazole Compounds

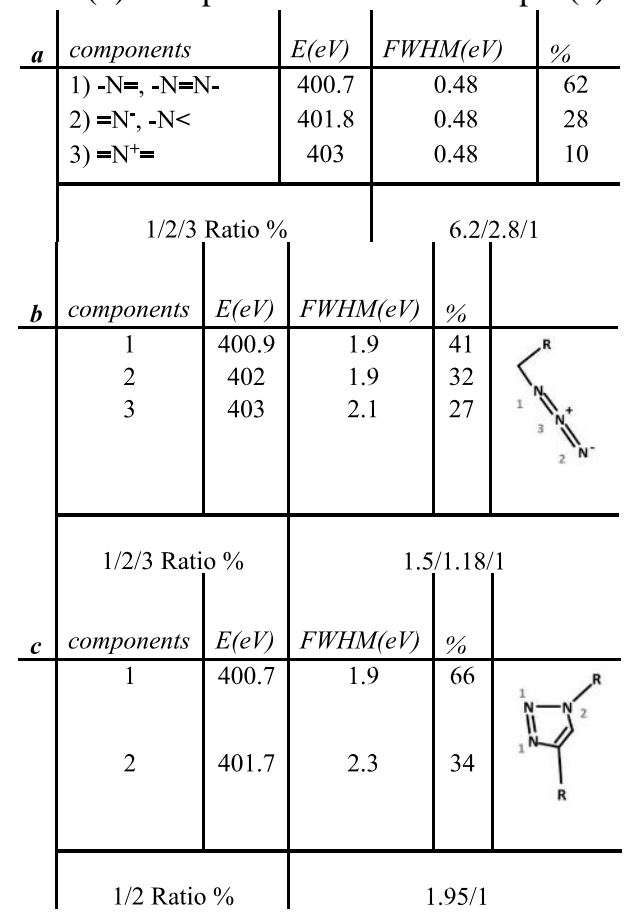

Table 2. Characteristic DSC Values of Modified and Unmodified Silk Fibroin Hydrogels and Reagents Involved ${ }^{a}$

\begin{tabular}{|c|c|c|c|}
\hline hydrogels & $\begin{array}{l}\text { Texo } \\
{ }^{\circ} \mathrm{C}\end{array}$ & $\begin{array}{l}\mathrm{T}_{\mathrm{g}} \\
{ }^{\circ} \mathrm{C}\end{array}$ & $\frac{\mathrm{T}_{\mathrm{d}}}{{ }^{\circ} \mathrm{C}}$ \\
\hline SF & 230 & 205 & 279 \\
\hline azide $\mathrm{SF}$ & 230 & 205 & 277 \\
\hline azide SF-IK & 225 & 195 & 279 \\
\hline BMS & 226 & 175 & 280 \\
\hline $\mathrm{Col}(\mathrm{IV})$ & & & 210 \\
\hline 4-azidoaniline hydrochloride & 165 & & 225 \\
\hline
\end{tabular}

to $1229 \mathrm{~cm}^{-1}$ are related to the $\beta$-sheet transitions. The decrease in the band at $1415 \mathrm{~cm}^{-1}$, corresponding to the $\mathrm{C}-\mathrm{OH}$ bending vibration, ${ }^{5,38,41,42}$ is probably also a consequence of the $\beta$-sheet transition due to the sonication treatment.

The modulated DSC curves of lyophilized silk fibroin-based hydrogels (SF, Azide SF, Azide SF-IK, and BMS), 4azidoaniline hydrochloride reagent (4-Az), and Col(IV) were acquired to observe the structural changes of SF after each reaction and confirm the data of CPMAS NMR and ATRFTIR analyses. Table 2 reports the characteristic thermal values shown in Figure 6. 
For 4-azidoaniline hydrochloride, the heat flow curve displays a sharp exothermic peak at around $165^{\circ} \mathrm{C}$ followed by a large endothermic peak centered at about $225^{\circ} \mathrm{C}$. This exothermic peak is the sum of the endothermic melting at $165^{\circ} \mathrm{C}$ and of a larger exothermic phenomenon well marked in the nonreversible heat flow curve (figure not reported), probably due to the decomposition of the azide. A further and final degradation occurs at around $225^{\circ} \mathrm{C}$.
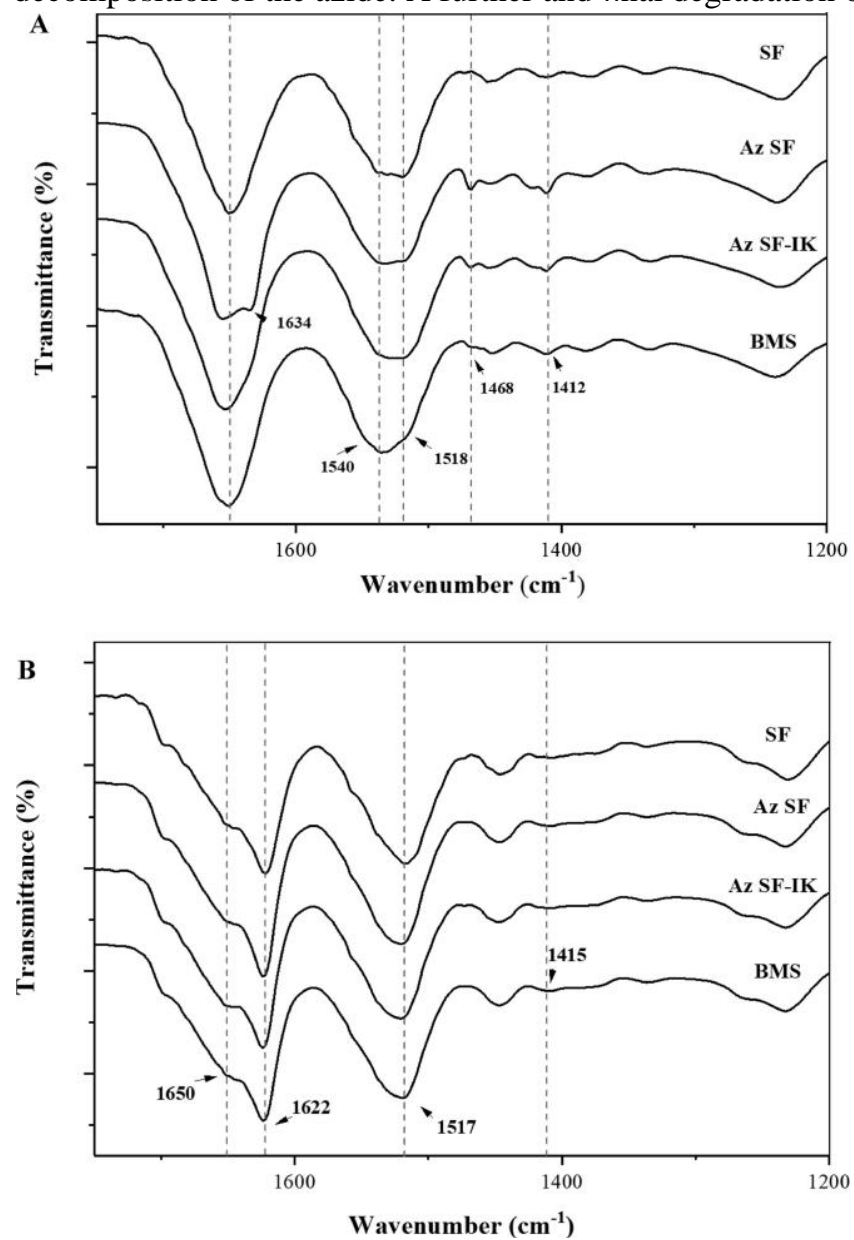

Figure 5. ATR-FTIR spectra of (a) lyophilized SF-based solution and (b) hydrogels.

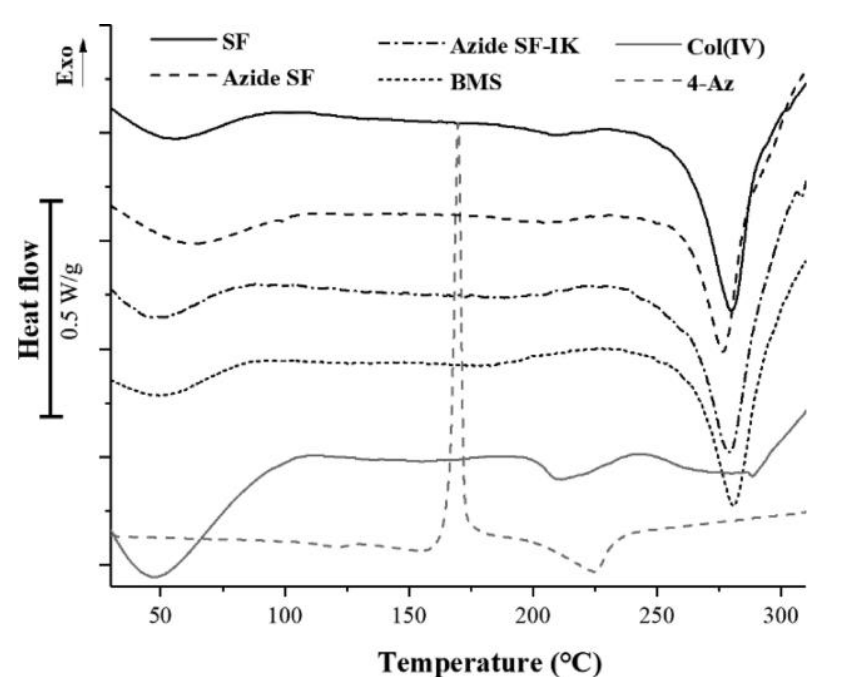

Figure 6. Modulated DSC curves of 4-azidoaniline hydrochloride (4Az), Col(IV), and lyophilized silk fibroin-based hydrogels. 
In all curves of the SF-containing samples and of Col(IV), the wide endothermic irreversible peaks centered at about 50- 60 ${ }^{\circ} \mathrm{C}$ are due to the evaporation of water from the freeze-dried materials.

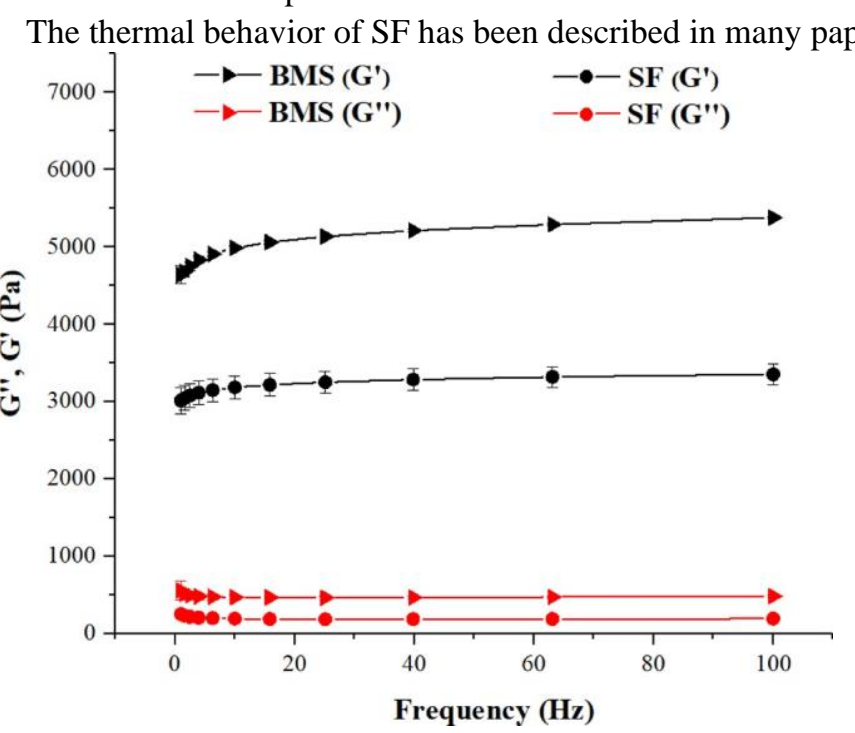

Figure 7. Rheological evaluation of the storage and loss modulus in the range of 1-100 Hz of unmodified and modified silk fibroin.

recently, the effect of annealing treatment on SF transition has been investigated by thermal and dynamic mechanical analysis. ${ }^{44}$ Depending on the structure, $\mathrm{T}_{\mathrm{g}}$ values ranging from about $170{ }^{\circ} \mathrm{C}$ to about $200{ }^{\circ} \mathrm{C}$ have been reported. Accordingly, our analyses place the SF glass transition at around $200{ }^{\circ} \mathrm{C}$, which is followed by the exothermic crystallization centered at about $225^{\circ} \mathrm{C}$ and a final endothermic degradation at $279^{\circ} \mathrm{C}$. Similar values have been detected for the azide-conjugated SF.

The introduction of IK in the SF chain causes a slight decrease in the polymer glass transition temperature and correspondingly an earlier crystallization.

More noticeable changes take place in the final BMS, whose $\mathrm{T}_{\mathrm{g}}$ values lowers to about $175^{\circ} \mathrm{C}$, with an earlier beginning of the crystallization phenomenon. Worth nothing is the fact that the endothermic peak of denaturation for Col(IV) that occurred at about $215^{\circ} \mathrm{C}$ is not visible in the final BMS polymer.

Rheological tests made on SF and BMS hydrogels (Figure 7) confirmed the gel-like structure of the materials $\left(\mathrm{G}^{\prime}>\mathrm{G}^{\prime \prime}\right)$ and reveal a noticeable increase in the elastic modulus of BMS with respect to SF (about $5 \mathrm{kPa}$ vs $3 \mathrm{kPa}$ ), both near the stiffness of the glomerular BM. ${ }^{45}$

The stiffness of hydrogels is an important factor to consider in regulating stem-cell fate. Mimicking the stiffness of a specific tissue, the differentiation fate of stem cells can be regulated and directed toward those tissue-specific cells. ${ }^{4}$

Thermogravimetric analysis (TGA) indicates that the amount of water in those hydrogels ranges around 95-96 wt \%, with a much slower water loss kinetics for SF as a consequence of its tighter crystalline structure and the larger presence of hydrogen bonds.

As preliminary evaluation of cell behavior in response to fibroin functionalization, adhesion, cell morphology, and metabolic activity were assessed on MRC5 cultures up to 7 days on films and hydrogels of SF and BMS. The fibroblast cell line is often used for biocompatibility testing, and changes in early adhesion can prove the presence of a bioactive surface.$^{46}$ The results summarized in Figure 8a,b clearly show the formation of adhered cell spindle shape typical of fibroblast activation when cells are cultured on BMS films (BMS-f) already at day 1, whereas a round shape is mainly observed for SF films (SF-film) at the first experimental time point as well as for SF and BMS hydrogels (SF-h and BMS-h). At days 3 and 7, the substrates fabricated of BMS seem to sensibly increase cell 


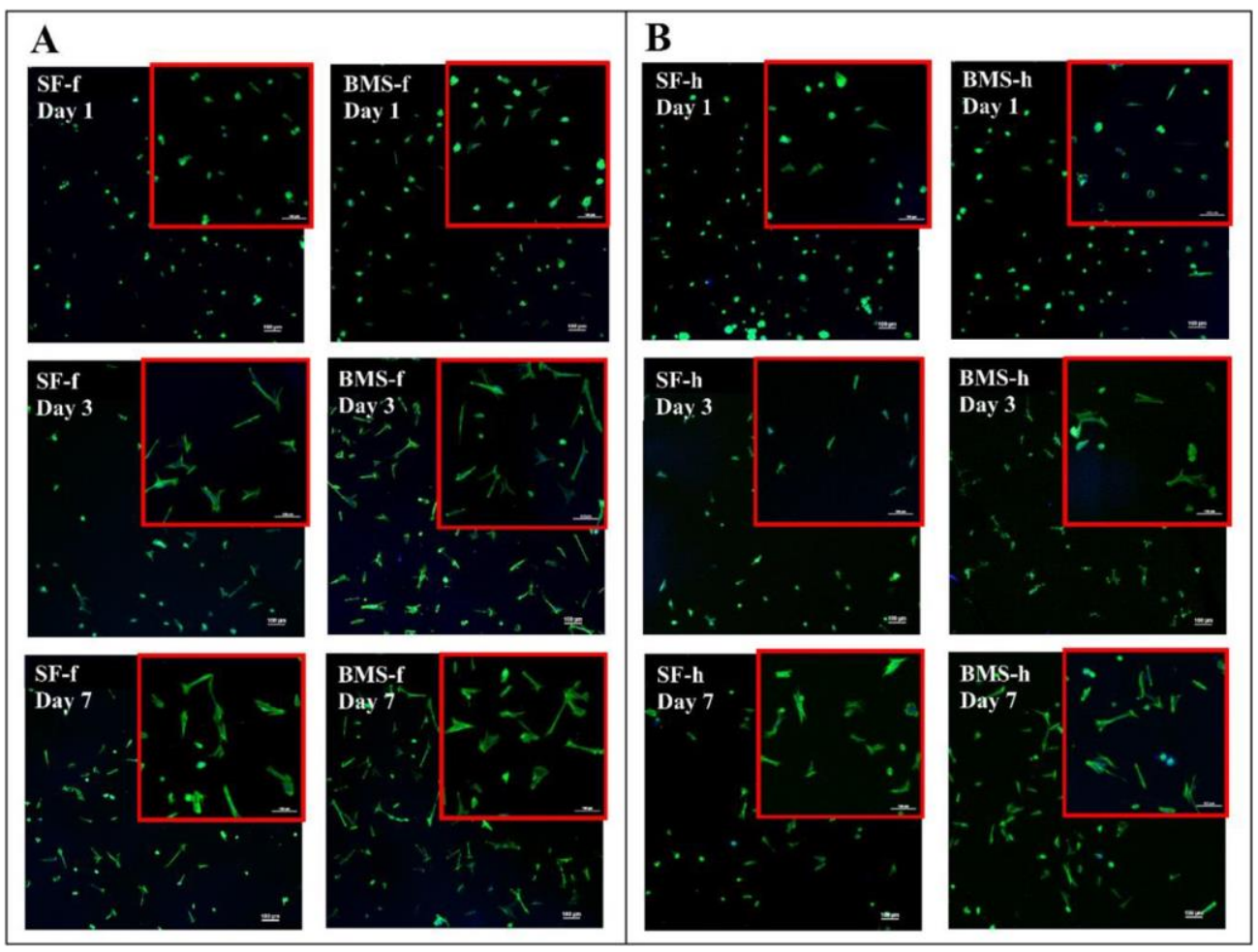

Figure 8. Early adhesion of MRC5 on (a) modified and unmodified films and (b) hydrogels at different time points (1, 3, and 7 days) (h: hydrogel; f: film).

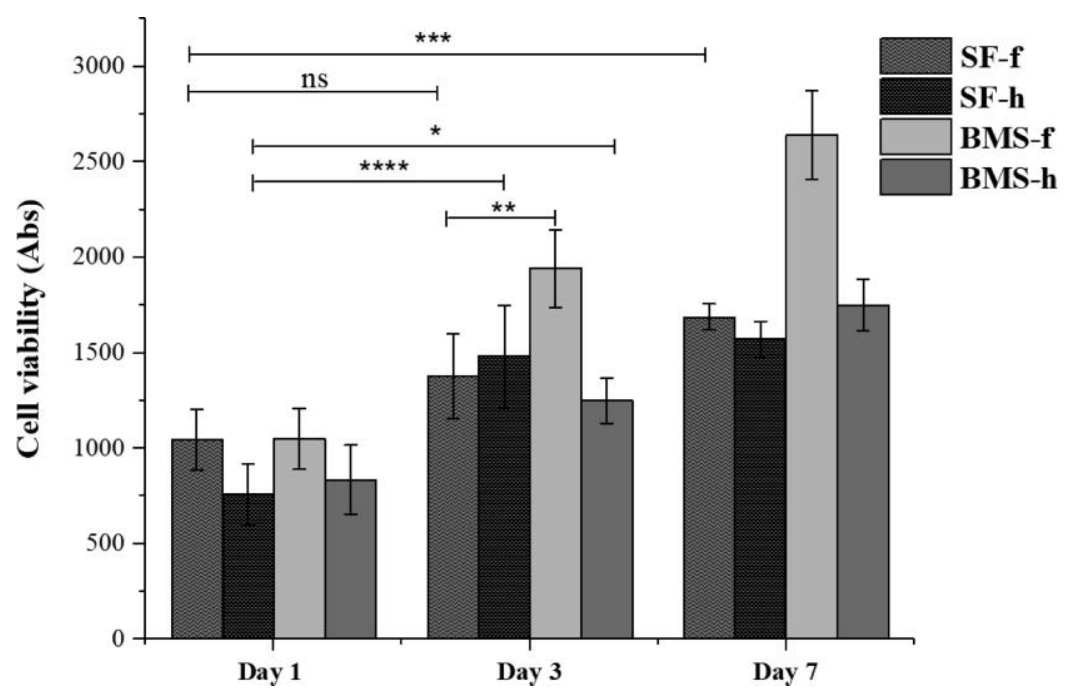

Figure 9. Alamar Blue assay for the evaluation of the cell viability of MRC5 cultured on modified (BMS) and unmodified fibroin (SF) films (f) and hydrogels (h) at days 1,3 , and 7. $\left({ }^{*} \mathrm{p}<0.05,{ }^{* *} \mathrm{p}<0.01,{ }^{* * *} \mathrm{p}<0.001,{ }^{* * * *} \mathrm{p}<0.0001\right.$, ns $=$ not significant).

spreading and cell-cell connection notably in BMS-f. Instead, the number of cells determined by 4',6-diamidino-2-phenylindole (DAPI) fluorescence staining (Supporting Information) revealed a slight increase in cell growth solely on films and a constant number of cells in hydrogels. Alamar Blue data (Figure 9) show a similar trend on all samples, with an increase in cell metabolic activity from day 1 to day 7 . However, despite the low proliferation rate, significantly higher values on sample BMC-f were detected, in particular at days 3 and 7. Results are in well agreement with confocal imaging results, confirming the positive impact of the functionalization on cell adhesion, spreading, and, most interestingly, metabolic activity. The highest metabolic activity values observed in BMS-f cell cultures are mainly due to the higher density of functional groups exposed to cells, if compared with hydrogels. In addition, it should be underlined that the biological impact of the modified SF hydrogels on adhesion of MRC5 can be also due to other factors, such as surface energy, water content, and also surface mechanical stiffness. 


\section{CONCLUSIONS}

In this study, a bio-inspired multifunctionalized silk fibroin was successfully synthesized and characterized in detail. TNBS tests and XPS analysis quantitatively estimated the efficiency of Col(IV) modification with DBCO groups (about 52\%) and SPAAC reaction (about 63\%). Data about changes in fibroin conformation revealed that the presence of IK peptide and Col(IV) in the structure created a less compact crystalline structure, as confirmed by spectroscopic analysis. In contrast, the physical cross-linking of the BMS solution by sonication increased the storage modulus of the BMS hydrogel of about $2 \mathrm{kPa}$ with respect to the SF hydrogel in the range of the mechanical properties of the glomerular BM.

Preliminary biological evaluations were performed by culturing MRC5 cells as a cellular model to verify the influence of the fibroin functionalization on early cell bioactivity. A significant increase in cell adhesion, spreading, viability, and cell-cell interaction was observed in BMS films compared to the unmodified SF. To further enhance cellular activity within the scaffolds, even mechanical properties and water content will be tuned depending on the intended application. ${ }^{47,48}$

\section{ASSOCIATED CONTENT}

* Supporting Information

The Supporting Information is available free of charge at https://pubs.acs.org/doi/10.1021/acsbiomaterials.0c01567.

Evaluation of free amine concentration in SF- and Col(IV)-based compounds, DLS analysis of SF solutions, and counting cells on confocal images acquired (PDF)

\section{AUTHOR INFORMATION}

\section{Corresponding Author}

Antonella Motta - Department of Industrial Engineering,

University of Trento, 38123 Trento, Italy; BIOTech Research

Center, University of Trento, 38123 Trento, Italy;

Email: antonella.motta@unitn.it

\section{Authors}

Sofia Santi - Department of Industrial Engineering, University of Trento, 38123 Trento, Italy; BIOTech Research Center, University of Trento, 38123 Trento, Italy; $\odot$ orcid.org/

0000-0002-5338-2730

Ines Mancini - Laboratory of Bioorganic Chemistry, Department of Physics, University of Trento, 38123 Trento, Italy

Sandra Dirè - Department of Industrial Engineering, University of Trento, 38123 Trento, Italy; "Klaus Mueller" Magnetic Resonance Laboratory, Department of Industrial Engineering, University of Trento, 38123 Trento, Italy; $\odot$ orcid.org/0000-0002-6000-6231

Emanuela Callone - Department of Industrial Engineering,

University of Trento, 38123 Trento, Italy; "Klaus Mueller" Magnetic Resonance Laboratory, Department of Industrial Engineering, University of Trento, 38123 Trento, Italy

Giorgio Speranza - Department of Industrial Engineering,

University of Trento, 38123 Trento, Italy; FBK-irst, 38123

Trento, Italy; IFN - CNR, CSMFO Lab. \& FBK CMM,

38123 Trento, Italy; • orcid.org/0000-0003-1478-0995

Nicola Pugno - Laboratory of Bio-Inspired, Bionic, Nano, 
Meta Materials \& Mechanics, Department of Civil,

Environmental and Mechanical Engineering, University of

Trento, 38123 Trento, Italy; School of Engineering and

Materials Science, Queen Mary University of London, E1-

4NS London, United Kingdom; ๑ orcid.org/0000-0003-

2136-2396

Claudio Migliaresi - Department of Industrial Engineering,

University of Trento, 38123 Trento, Italy; BIOTech Research

Center, University of Trento, 38123 Trento, Italy

Complete contact information is available at:

https://pubs.acs.org/10.1021/acsbiomaterials.0c01567

\section{Author Contributions}

The manuscript was written through contributions of all authors. All authors have given approval to the final version of the manuscript.

Notes

The authors declare no competing financial interest.

\section{ACKNOWLEDGMENTS}

This research has been supported by REMIX, funded by the European Union's Horizon 2020 research and innovation programme under the Maria Sklodowska-Curie grant agreement no. 778078. The authors thank Marta Marchioretto for assistance in dynamic light scattering measurements.

\section{REFERENCES}

(1) Inoue, S.; Tanaka, K.; Arisaka, F.; Kimura, S.; Ohtomo, K.; Mizuno, S. Silk Fibroin of Bombyx Mori Is Secreted, Assembling a High Molecular Mass Elementary Unit Consisting of H-Chain, LChain, and P25, with a 6:6:1 Molar Ratio. J. Biol. Chem. 2000, 275, 40517-40528.

(2) Floren, M.; Migliaresi, C.; Motta, A. Processing Techniques and Applications of Silk Hydrogels in Bioengineering. J. Funct. Biomater. 2016, 7, 26.

(3) Servoli, E.; Maniglio, D.; Motta, A.; Predazzer, R.; Migliaresi, C. Surface Properties of Silk Fibroin Films and Their Interaction with Fibroblasts. Macromol. Biosci. 2005, 5, 1175-1183.

(4) Sun, W.; Incitti, T.; Migliaresi, C.; Quattrone, A.; Casarosa, S.; Motta, A. Viability and Neuronal Differentiation of Neural Stem Cells Encapsulated in Silk Fibroin Hydrogel Functionalized with an IKVAV Peptide. J. Tissue Eng. Regener. Med. 2017, $11,1532-1541$.

(5) Partlow, B. P.; Tabatabai, A. P.; Leisk, G. G.; Cebe, P.; Blair, D. L.; Kaplan, D. L. Silk Fibroin Degradation Related to Rheological and Mechanical Properties. Macromol. Biosci. 2016, 16, 666-675.

(6) Sekiguchi, $\quad$ R.; $\quad$ Yamada, K. M. BasementMembranes in

Development and Disease. In Current topics in developmental biology; 1st ed.; Elsevier Inc.: 2018; Vol. 130, DOI: 10.1016/ bs.ctdb.2018.02.005.

(7) Cruz-Acuña, R.; García, A. J. Synthetic Hydrogels Mimicking Basement Membrane Matrices to Promote Cell-Matrix Interactions. Matrix Biol. 2017, 57-58, 324-333.

(8) Lebleu, V. S.; Macdonald, B.; Kalluri, R. Structure and Function of Basement Membranes. Exp. Biol. Med. $2007,232,1121$.

(9) Mak, K. M.; Mei, R. Basement Membrane Type IV Collagen and Laminin: An Overview of Their Biology and Value as Fibrosis Biomarkers of Liver Disease. Anat. Rec. 2017, 300, 1371-1390.

(10) Hippocampus, C. N. S.; Zhao, C.; Toni, N.; Gage, F. H. Axon Regeneration. In Cellular Migration and Formation of Neuronal Connections; Academic Press, 2013, 2, 723-738, DOI: 10.1016/ B978-0-12-397266-8.00004-1.

(11) Baines, R. A.; Seugnet, L.; Thompson, A.; Salvaterra, P. M.; Bate, M. Regulation of Synaptic Connectivity: Levels of Fasciclin II Influence Synaptic Growth in the Drosophila CNS. J. Neurosci. 2002, 22, 6587-6595.

(12) Cholas, R. H.; Hsu, H.-P.; Spector, M. The Reparative Response to Cross-Linked Collagen-Based Scaffolds in a Rat Spinal Cord Gap Model. Biomaterials 2012, 33, 2050-2059. 
(13) Cao, J.; Sun, C.; Zhao, H.; Xiao, Z.; Chen, B.; Gao, J.; Zheng, T.; Wu, W.; Wu, S.; Wang, J.; Dai, J. The Use of Laminin Modified Linear Ordered Collagen Scaffolds Loaded with Laminin-Binding Ciliary Neurotrophic Factor for Sciatic Nerve Regeneration in Rats. Biomaterials 2011, 32, 3939-3948.

(14) Yao, L.; Damodaran, G.; Nikolskaya, N.; Gorman, A. M.; Windebank, A.; Pandit, A. The Effect of Laminin Peptide Gradient in Enzymatically Cross-Linked Collagen Scaffolds on Neurite Growth. J. Biomed. Mater. Res., Part A 2010, 9999A, 484.

(15) Tsintou, M.; Dalamagkas, K.; Seifalian, A. M. Advances in Regenerative Therapies for Spinal Cord Injury: A Biomaterials Approach. Neural Regener. Res. 2015, 10, 726-742.

(16) Lein, P. J.; Higgins, D.; Turner, D. C.; Flier, L. A.; Terranova, V. P. The NC1 domain of type IV collagen promotes axonal growth in sympathetic neurons through interaction with the $\alpha 1 \beta 1$ integrin. J. Cell Biol. 1991, 113, 417-428.

(17) Zeng, Z. S.; Cohen, A. M.; Guillem, J. G. Loss of Basement Membrane Type IV Collagen Is Associated with Increased Expression of Metalloproteinases 2 and 9 (MMP-2 and MMP-9) during Human Colorectal Tumorigenesis. Carcinogenesis 1999, 20, 749-755.

(18) Sashina, E. S.; Bochek, A. M.; Novoselov, N. P.; Kirichenko, D. A. Structure and Solubility of Natural Silk Fibroin. Russ. J. Appl. Chem. 2006, 79, 869-876.

(19) Zhao, H.; Heusler, E.; Jones, G.; Li, L.; Werner, V.; Germershaus, O.; Ritzer, J.; Luehmann, T.; Meinel, L. Decoration of Silk Fibroin by Click Chemistry for Biomedical Application. J. Struct. Biol. 2014, 186, 420-430.

(20) Raggio, R.; Bonani, W.; Callone, E.; Dire, S.; Gambari, L.; Grassi, F.; Motta, A. Silk Fibroin Porous Scaffolds Loaded with a SlowReleasing Hydrogen Sulfide Agent (GYY4137) for Applications of Tissue Engineering. ACS Biomater. Sci. Eng. 2018, 4, $2956-2966$.

(21) Hermanson, G. T. Bioconjugate Techniques; 2nd Edition; 2008, Vol. 91.

(22) Com, U. TNBSA Reagent for Amine Detection TNBSA 5\% Solution. No. 2008, 1982, 1-2.

(23) Thermo Fisher Scientific Inc. INSTRUCTIONS TNBSA

(2,4,6-Trinitrobenzene Sulfonic Acid). 2008, 1-2.

(24) Wang, X.; Kluge, J. A.; Leisk, G. G.; Kaplan, D. L. SonicationInduced Gelation of Silk Fibroin for Cell Encapsulation. Biomaterials 2008, 29, 1054-1064.

(25) R: The R Project for Statistical Computing https://www.rproject.org/. (accessed Sep 24, 2019)

(26) Asakura, T.; Suita, K.; Kameda, T.; Afonin, S.; Ulrich, A. S. Structural Role of Tyrosine in Bombyx Mori Silk Fibroin, Studied by Solid-State NMR and Molecular Mechanics on a Model Peptide Prepared as Silk I and II. Magn. Reson. Chem. 2004, 42, 258-266.

(27) Venancio, T.; Oliveira, L. M.; Pawlak, T.; Ellena, J.; Boechat, N.; Brown, S. P. The Use of Variable Temperature ${ }^{13} \mathrm{C}$ Solid-State MAS NMR and GIPAW DFT Calculations to Explore the Dynamics of Diethylcarbamazine Citrate. Magn. Reson. Chem. 2019, 57, 200210 .

(28) Darsy, G.; Bouzat, F.; Muñoz, M.; Lucas, R.; Foucaud, S.; Diogo, C. C.; Babonneau, F.; Leconte, Y.; Maître, A. Monitoring a Polycycloaddition by the Combination of Dynamic Rheology and FTIR Spectroscopy. Polymer 2015, 79, 283-289.

(29) Callone, E.; Dire, S.; Hu, X.; Motta, A . Processing Influence on Molecular Assembling and Structural Conformations in Silk Fibroin: Elucidation by Solid-State NMR. ACS Biomater. Sci. Eng. 2016, 2, 758-767.

(30) Tang, X.; Qiao, X.; Miller, R.; Sun, K. Effect of Ionic Strength on the Interfacial Viscoelasticity and Stability of Silk Fibroin at the Oil/Water Interface. J. Sci. Food Agric. 2016, 96, 4918-4928.

(31) Paquin, F.; Rivnay, J.; Salleo, A.; Stingelin, N.; Silva-Acuña, C. Multi-phase microstructures drive exciton dissociation in neat semicrystalline polymeric semiconductors. J. Mater. Chem. C 2015, 3, 10715-10722.

(32) Vanea, E.; Simon, V. XPS Study of Protein Adsorption onto Nanocrystalline Aluminosilicate Microparticles. Appl. Surf. Sci. 2011, 257, 2346-2352.

(33) Browne, M. M.; Lubarsky, G. V.; Davidson, M. R.; Bradley, R. H. Protein Adsorption onto Polystyrene Surfaces Studied by XPS and AFM. Surf. Sci. 2004, 553, 155-167.

(34) Coates, M.; Elamari, H.; Girard, C.; Griveau, S.; Nyokong, T.; Bedioui, F. 4-Azidoaniline-Based Electropolymer as a Building Block for Functionalisation of Conductive Surfaces. J. Electroanal. Chem. 2012, 670, 79-84.

(35) Lee, H. J.; Fernandes-Cunha, G. M.; Putra, I.; Koh, W.-G.; Myung, D. Tethering Growth Factors to Collagen Surfaces Using Copper-Free Click Chemistry: Surface Characterization and in Vitro Biological Response. ACS Appl. Mater. Interfaces 2017, 9, 2338923399.

(36) Fortgang, P.; Tite, T.; Barnier, V.; Zehani, N.; Maddi, C.; Lagarde, F.; Loir, A.-S.; Jaffrezic-Renault, N.; Donnet, C.; Garrelie, F.; Chaix, C. Robust Electrografting on Self-Organized 3D Graphene Electrodes. ACS Appl. Mater. Interfaces 2016, 8, 1424.

(37) Silva, R.; Singh, R.; Sarker, B.; Papageorgiou, D. G.; Juhasz, J. A.; Roether, J. A.; Cicha, I.; Kaschta, J.; Schubert, D. W.; Chrissafis, K.; Detsch, R.; Boccaccini, A. R. Soft-Matrices Based on Silk Fibroin and Alginate for Tissue Engineering. Int. J. Biol. Macromol. 2016, 93, $1420-1431$.

(38) Matsumoto, A.; Chen, J.; Collette, A. L.; Kim, U.-J.; Altman, G. H.; Cebe, P.; Kaplan, D. L. Mechanisms of Silk Fibroin Sol-Gel Transitions. J. Phys. Chem. B 2006, 110, 21630-21638.

(39) Rajabi, M.; Firouzi, M.; Hassannejad, Z.; Haririan, I.; Zahedi, P. Fabrication and Characterization of Electrospun LamininFunctionalized Silk Fibroin/Poly(Ethylene Oxide) Nanofibrous Scaffolds for Peripheral Nerve Regeneration. J. Biomed. Mater. Res., Part B 2018, 106, 1595-1604.

(40) Xu, Y.; Lu, Y.; Dai, X.; Dong, B. The Influence of OrganicBinding Metals on the Biogas Conversion of Sewage Sludge. Water Res. 2017, 126, 329-341.

(41) Qin, Z.; Buehler, M. J. Molecular Dynamics Simulation of the $\alpha$-Helix to $\beta$-Sheet Transition in Coiled Protein Filaments: Evidence for a Critical Filament Length Scale. Phys. Rev. Lett. 2010, 104, 198304. 
(42) Litvinov, R. I.; Faizullin, D. A.; Zuev, Y. F.; Weisel, J. W. The $\alpha$ Helix to $\beta$-Sheet Transition in Stretched and Compressed Hydrated Fibrin Clots. Biophys. J. 2012, 103, 1020-1027.

(43) Magoshi, J.; Magoshi, Y.; Nakamura, S.; Kasai, N.; Kakudo, M. Physical properties and structure of silk. V. Thermal behavior of silk fibroin in the random-coil conformation. J. Polym. Sci., Polym. Phys. Ed. 1977, 15, 1675-1683.

(44) Motta, A.; Fambri, L.; Migliaresi, C. Regenerated Silk Fibroin Films: Thermal and Dynamic Mechanical Analysis. Macromol. Chem. Phys. 2002, 203, 1658-1665.

(45) Hu, M.; Azeloglu, E. U.; Ron, A.; Tran-Ba, K.-H.; Calizo, R. C.; Tavassoly, I.; Bhattacharya, S.; Jayaraman, G.; Chen, Y.; Rabinovich, V.; Iyengar, R.; Hone, J. C.; He, J. C.; Kaufman, L. J. A Biomimetic Gelatin-Based Platform Elicits a pro-Differentiation Effect on Podocytes through Mechanotransduction. Sci. Rep. 2017, 7, 43934.

(46) Zange, R.; Kissel, T. Comparative in Vitro Biocompatibility Testing of Polycyanoacrylates and Poly(D,L-Lactide-Co-Glycolide) Using Different Mouse Fibroblast (L929) Biocompatibility Test Models. Eur. J. Pharm. Biopharm. 1997, 44, $149-157$.

(47) Haugh, M. G.; Murphy, C. M.; McKiernan, R. C.; Altenbuchner, C.; O’Brien, F. J. Crosslinking and Mechanical Properties Significantly Influence Cell Attachment, Proliferation, and Migration within Collagen Glycosaminoglycan Scaffolds. Tissue Eng., Part A 2011, 17, 1201-1208.

(48) Pina, S.; Ribeiro, V. P.; Marques, C. F.; Maia, F. R.; Silva, T. H.; Reis, R. L.; Oliveira, J. M. Scaffolding Strategies for Tissue Engineering and Regenerative Medicine Applications. Materials 2019, 12, 1824. 


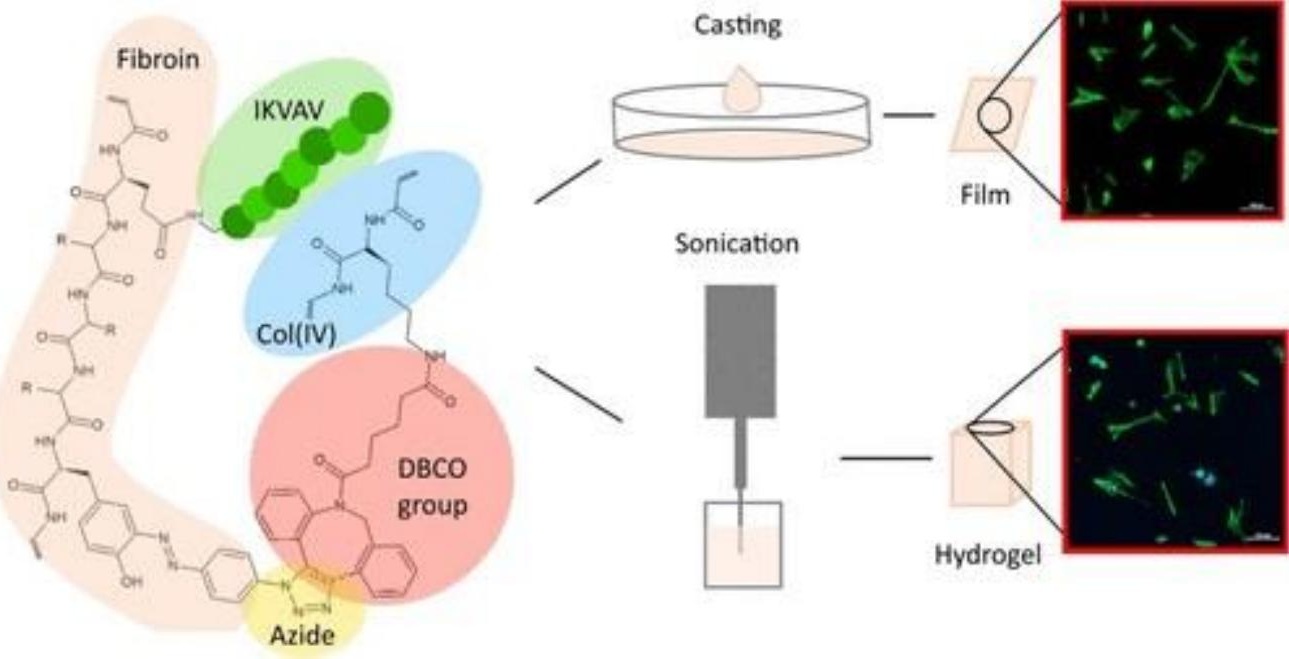

